\title{
Influence of boundary conditions on the out-of-plane response of brick masonry walls in buildings with RC slabs
}

\author{
Marco Tondelli ${ }^{1}$, Katrin Beyer ${ }^{1, *}{ }^{\dagger}$ and Matthew DeJong ${ }^{2}$ \\ ${ }^{1}$ Earthquake Engineering and Structural Dynamics Laboratory (EESD), School of Architecture, Civil and Environmental \\ Engineering (ENAC), École Polytechnique Fédérale de Lausanne, Lausanne, Switzerland \\ ${ }^{2}$ Department of Engineering, University of Cambridge, Cambridge, UK
}

\begin{abstract}
SUMMARY
In modern unreinforced masonry buildings with stiff RC slabs, walls of the top floor are most susceptible to out-of-plane failure. The out-of-plane response depends not only on the acceleration demand and wall geometry but also on the static and kinematic boundary conditions of the walls. This paper discusses the influence of these boundary conditions on the out-of-plane response through evaluation of shake table test results and numerical modelling. As a novum, it shows that the in-plane response of flanking elements, which are orthogonal to the wall whose out-of-plane response is studied, has a significant influence on the vertical restraint at the top of the walls. The most critical configuration exists if the flanking elements are unreinforced masonry walls that rock. In this case, the floor slabs can uplift, and the out-of-plane loadbearing walls loose the vertical restraint at the top. Numerical modelling confirms this experimentally observed behaviour and shows that slab uplift and the difference in base and top excitation have a strong influence on the out-of-plane response of the walls analysed. Copyright @ 2016 John Wiley \& Sons, Ltd.
\end{abstract}

Received 30 September 2015; Revised 23 December 2015; Accepted 5 January 2016

KEY WORDS: unreinforced masonry; out-of-plane behaviour; rocking; boundary conditions; discrete element analysis; shake table test

\section{INTRODUCTION}

Under earthquake loading, modern unreinforced masonry (URM) buildings typically fail because of inplane failure of the lower storey walls or because of out-of-plane failure of walls of the top storeys. In this paper, the out-of-plane failure of the top storey walls in modern URM buildings with stiff RC floor slabs is investigated. The focus of this investigation lies on the boundary conditions that the RC slabs provide to the URM walls. More specifically, the paper investigates the influence of the in-plane deformations of flanking walls on these boundary conditions.

Hence, the paper treats the interaction of in-plane and out-of-plane URM wall responses. The interaction of in-plane and out-of-plane responses has also been recently studied for URM infills [1-5] and URM walls [6, 7]. However, these studies consider the coupling of the in-plane and out-of-plane responses of the same wall element when subjected to bidirectional excitation. Here, a URM building subjected to only a unidirectional excitation is considered, and the influence of the response of walls that are loaded in plane on the boundary conditions of the walls that are loaded out of plane is investigated. The paper focuses on modern URM walls constructed with hollow-core clay bricks and cement mortar joints of normal thickness $(\sim 1 \mathrm{~cm})$.

*Correspondence to: Katrin Beyer, Earthquake Engineering and Structural Dynamics Laboratory (EESD), School of Architecture, Civil and Environmental Engineering (ENAC), École Polytechnique Fédérale de Lausanne, Lausanne, Switzerland.

†E-mail: katrin.beyer@epfl.ch 
The literature reports several experimental campaigns that investigate the dynamic out-of-plane behaviour of brick masonry walls under seismic excitation. An extensive study was carried out by the consortium ABK [8], in which 22 URM walls with different height-to-thickness ratios were tested dynamically. The walls, which had rectangular cross sections, were built with different types of units (grouted clay bricks and grouted and ungrouted concrete blocks). The horizontal input motions applied at the top and bottom of the walls were obtained from nonlinear analyses of a onestorey URM building using actual earthquake ground motions. The walls were pinned at the base while the top of the walls was free to rotate and displace vertically. An additional mass was placed on the top of the walls to simulate the weight of additional structural elements. The authors observed that after the formation of a mechanism, the walls did not collapse immediately but developed a stable rocking mechanism with displacements significantly larger than before the onset of rocking.

Griffith et al. [9] performed both static and dynamic tests on half-scale clay brick walls characterised by rectangular cross section and two different values of thickness. The test apparatus was composed of a shake table with a braced steel frame that provided lateral support to the top of the walls. The same displacement was imposed at the base and the top of the walls with the objective of representing boundary conditions of stiff floor diaphragms and neglecting in-plane drifts. The top of the walls was free to rotate and displace vertically. An axial load could be applied at the top of the wall by using six pretensioned springs. The test results underlined the importance of displacement rather than acceleration demand when determining whether a wall loaded out of plane will collapse under seismic loading. Meisl et al. [10] performed shake table tests on four clay brick multiwythe rectangular walls and also concluded that the peak displacement demand has a greater influence on out-of-plane collapse than the peak acceleration demand.

The investigation of the seismic response of an out-of-plane loaded URM wall element as a component of a global building system was the focus of the experimental test performed by Simsir et al. [11]. The authors performed shake table tests on a half-scale building composed of two out-ofplane URM walls and two in-plane reinforced masonry walls connected by floor diaphragms of varying stiffness. All walls had rectangular cross sections and were built with lightweight hollow concrete blocks. The out-of-plane loaded walls were free to rotate at their base while the top of the walls was free to rotate and displace vertically. The tests showed that diaphragm flexibility increased the out-of-plane displacement of the walls because increased flexibility resulted in an increase of the period and of the spectral displacement demand. In addition, the axial load and the wall mass significantly affected the out-of-plane response; collapse was observed only for the specimen subjected to reduced axial load and increased wall mass.

Dazio [12] carried out shake table tests that aimed at investigating the influence of boundary conditions on the out-of-plane response of URM walls. Six test units, all with rectangular cross sections but different wall widths and slenderness ratios, were constructed with hollow-core clay bricks and standard cement mortar. The test setup was designed to provide five different boundary conditions at the top of the walls: a 'simply supported' condition where the top of the wall was free to rotate and displace vertically, a 'fixed' condition where rotation and vertical displacement at the top of the wall were fully restrained and three intermediate conditions where the top support had varying values of axial and rotational stiffness and the axial load was applied with different eccentricities with regard to the wall axis. It was observed that the simply supported condition was not always the most critical but that an eccentric axial force can cause collapse for lower levels of shaking. Additionally, increased levels of axial load were found to favour a sudden transition from rocking to collapse.

Penner and Elwood [13] carried out a shake table test on five URM wall specimens to investigate the effect of flexible diaphragms. The test units were multiwythe rectangular walls built with solid brick units. The shake table setup included top and bottom springs that could be varied to represent different levels of diaphragms stiffness. The experimental campaign underlined that-dependent on the frequency content of the record and dynamic properties of the walls-walls connected to flexible diaphragms can be more stable than walls connected to stiff diaphragms. Additionally, it was observed that for some boundary conditions, the transition from rocking to collapse can occur very suddenly. 
The most recurrent parameters that were investigated by the experimental studies were the effect of wall slenderness $[8,9,12,13]$, axial load $[9,11,12]$ and flexible diaphragms $[10,11,13]$ on the out-ofplane response of URM walls. With the exception of Simsir et al. [11], who included in-plane loaded walls and the top slab in the test setup, all the aforementioned tests studied the out-of-plane behaviour analysing the walls as single elements, separated from the rest of the structure. At the base, all studies placed the walls onto a foundation, which allowed the walls to rock. The tests were designed to provide idealised boundary conditions at the top of the out-of-plane loaded walls. The idealised boundary conditions at the top reflected in most cases a roller condition [8-11, 13]. Only Dazio [12] modified the pinned condition at the top to model a certain rotational restraint and an eccentric axial force. All studies applied the same motion at the top and the bottom support. Three studies $[10,11,13]$ placed springs between wall and support in order to account for deformations of flexible diaphragms, which resulted from the inertia force of the supported wall. It is interesting to note that none of the existing studies applied different motions at the top and the bottom in order to account for acceleration amplification over the height of the building because of in-plane deformation of walls that are orthogonal to the out-of-plane loaded walls.

Contrary to these previous studies, the aim of this paper is to investigate the influence of boundary conditions on the out-of-plane response of URM walls in buildings with stiff RC slabs and the effect that in-plane response of orthogonal walls has on the horizontal and vertical boundary conditions. In addition, the effect of different input motions at the top and bottom of the wall is investigated. In Section 2, the results of a unidirectional shake table test performed on a four-storey structure built at half scale will be presented, and the observations from the test will be discussed. The four-storey structure was designed to provide different types of boundary conditions to the out-of-plane load-bearing URM walls. The observations from this experimental campaign were the motivation to investigate these boundary conditions more systematically through a numerical study. Section 3 presents the validation of a discrete element model, which is analysed using the software UDEC [14]. The model is then used in Section 4 to investigate the relative influence of three key boundary conditions, that is, the difference in horizontal and vertical movements of the top and bottom slabs and the effect of a horizontal support at the top.

\section{EXPERIMENTAL CAMPAIGN}

The shake table test presented in this section is part of a larger research initiative focused on the study of the seismic behaviour of structures with RC and URM walls, where the two structural systems are coupled by RC slabs [15]. The test was carried out at the TREES Lab (Laboratory for Training and Research in Earthquake Engineering and Seismology) in Pavia (Italy), within the scope of a SERIES grant (Seismic Engineering Research Infrastructure for European Synergies) of the FP7 programme.
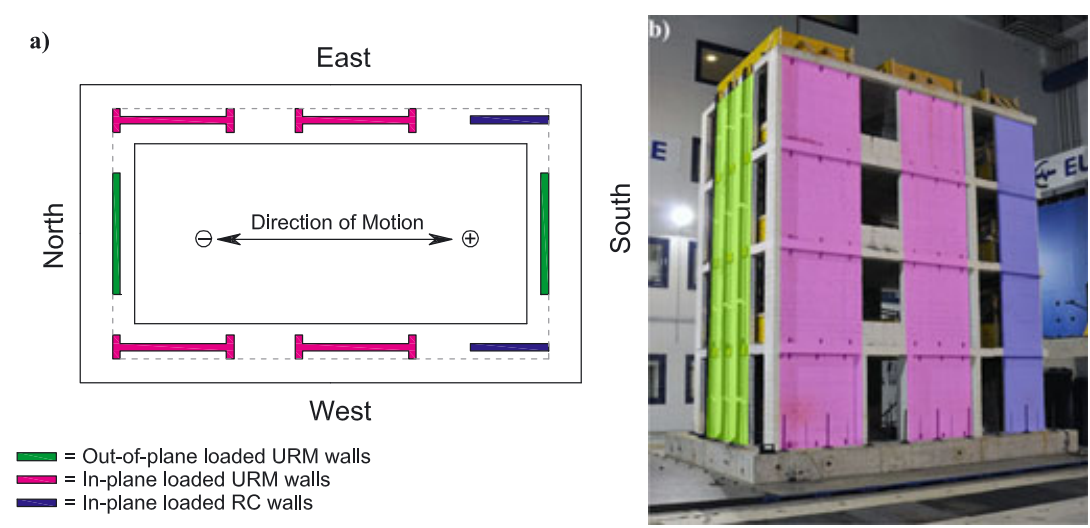

Figure 1. Test specimen: (a) plan view and (b) northwest view. 


\subsection{Test unit}

The test specimen was a four-storey structure built at half scale. The structure had a rectangular footprint and was symmetric along its longitudinal axis, that is, the direction along which the unidirectional motion was applied. The test specimen was composed of two RC walls and six URM walls, and these vertical elements were coupled by stiff RC slabs (Figure 1). Four out of the six URM walls were loaded in plane, and two out of plane (Figure 1). The plan distribution of the structural elements was conceived such as to provide different boundary conditions to the out-of-plane loaded URM walls of the north and the south faces: at the north face, the out-of-plane loaded URM walls were flanked by two in-plane loaded URM walls, while at the south face, the out-of-plane loaded URM walls were flanked by two in-plane loaded RC walls (Figure 1). The longitudinal reinforcement of the RC walls passed through the slabs, and the RC walls could therefore not rock on the slabs. The flanking elements, URM walls on one side and RC walls on the other, were expected to provide different vertical constraints to the RC slabs and therefore induce different vertical boundary conditions to the out-of-plane loaded URM walls.

To perform the test at a reduced scale, the artificial mass simulation scaling law was applied [16]. This law requires that at reduced scale, the stiffness, strength and deformation capacities of the construction materials are the same as at full scale. For the applied scaling factor of two, the density of all materials should have been doubled. However, this is generally impossible to achieve, and therefore, additional masses were added in the form of concrete blocks, which were placed on the four RC slabs. Lumping the additional mass reproduces the in-plane behaviour of the structure relatively accurately. In order to correctly scale the seismic response of the out-of-plane URM walls, it would have been necessary to 'smear' the additional mass that relates to these walls over their height. Instead, the additional mass for the out-of-plane loaded walls was also included by placing additional concrete blocks on the slabs, which effectively makes the URM walls less susceptible to out-of-plane failure. This mass lumping was carried out to ensure that the inplane seismic loading obeyed scaling laws and to avoid out-of-plane collapse prior to realisation of the full in-plane capacity. This was effective, as the first out-of-plane collapse of a URM wall was obtained in the final run, in which the in-plane loaded URM walls lost their axial load-bearing capacity and the test was stopped. Thus, the out-of-plane failure observed is qualitatively representative but may have occurred at lower ground acceleration levels in a fullscale building. Nevertheless, the simulations in the following sections were all representative of the as-built test specimen, so direct comparison is appropriate.
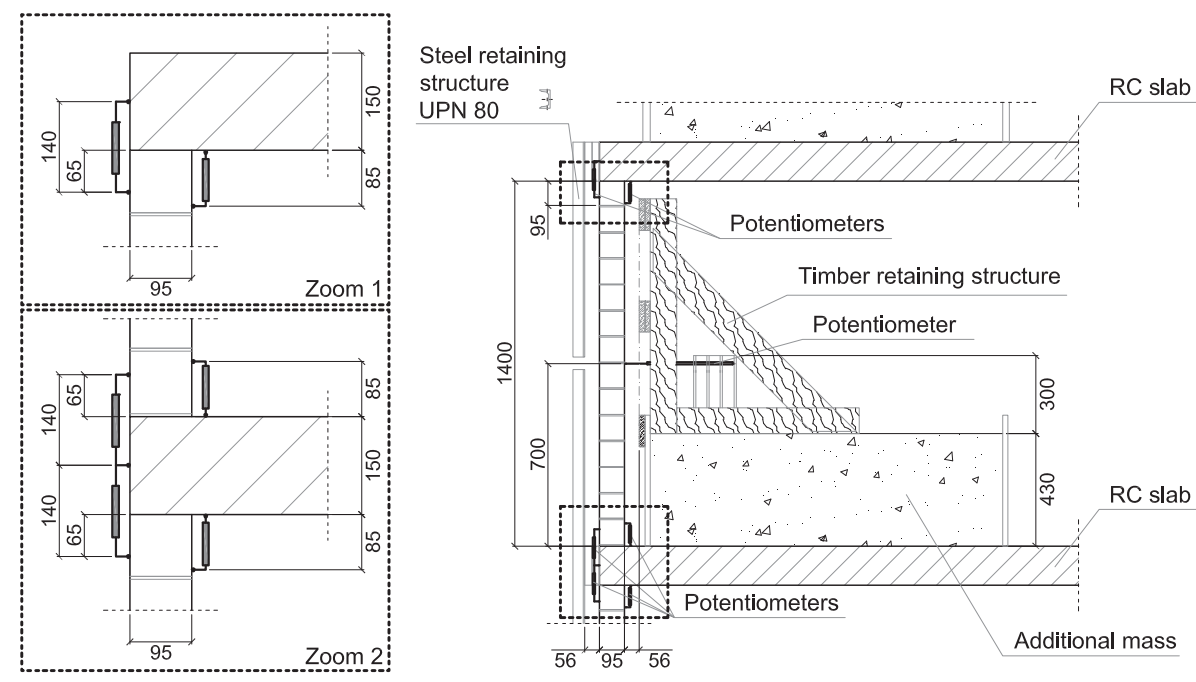

Figure 2. Vertical section of one of the out-of-plane loaded URM walls of the test specimen (dimensions in millimetre). 
The URM walls were constructed using half-scale hollow-core clay brick units that were specifically manufactured for this project. The units, with dimensions of $150 \times 95 \times 95 \mathrm{~mm}$, were assembled using a standard mortar of class M15; both horizontal and vertical joints were $5 \mathrm{~mm}$ thick. The brick units were designed to reproduce the behaviour of full-scale bricks in masonry walls that were subjected to inplane loading [17]. The out-of-plane loaded URM walls were $1.545 \mathrm{~m}$ long, $1.400 \mathrm{~m}$ high and $95 \mathrm{~mm}$ wide. A vertical section of these walls is shown in Figure 2.

Each out-of-plane loaded wall of the second, third and fourth storeys was instrumented with five potentiometers. One potentiometer measured the out-of-plane horizontal displacement at midheight of the walls; the latter was fixed to a support on the additional mass and therefore directly connected to the RC slab. Two additional potentiometers were used to measure the internal and external vertical displacements of the top and bottom rows of bricks and were connected to the RC slabs. An optical measurement system was employed to record the displacement response of the structure during shaking. This system [18] uses high-definition cameras to record the 2D displacement of reflecting markers that are glued to the structure and was used to record the in-plane displacements of the URM walls and RC slabs of the west façade of the structure.

Figure 2 shows the retaining structures that were installed on the outer and inner sides of the out-ofplane loaded URM walls. The purpose of these structures was to avoid the collapse of the walls onto the shake table. The retaining elements were installed at a clear distance of $56 \mathrm{~mm}$ from the walls (Figure 2), which corresponds to approximately $60 \%$ of the wall thickness, and therefore greater than the unstable point of static equilibrium for the out-of-plane mechanism.

\subsection{Ground motion, testing sequence and data set}

The input motion was the E-W component of the ground motion recorded at the Ulcinj-Hotel Albatros station during the 15 April 1979 Montenegro earthquake. The time axis of the record was divided by a factor of $\sqrt{2}$ to account for the fact that the test was carried out at half scale. The record was selected for its broad frequency content. Nine dynamic tests were performed with increasing value of peak ground acceleration (PGA), from 0.05 to $0.9 \mathrm{~g}$ (see Beyer et al. [19] for more details). Only the last two tests will be discussed in the following; these had the nominal PGAs of 0.7 and $0.9 \mathrm{~g}$, respectively. A description of the in-plane damage and comparison to the predicted response is presented by Beyer et al. [19]. Additionally, the full data set collected during the experimental campaign is publically available at 10.5281 /zenodo. 11578 .

\subsection{Visual observations of out-of-plane response of unreinforced masonry walls}

After each run, a survey of the structure was performed to investigate the progression of the level of damage to the structure. Up to run 8, some out-of-plane displacements occurred, but no residual damage was observed in the out-of-plane loaded URM walls. During the last test $(P G A=0.9 \mathrm{~g})$, significant out-of-plane displacements of the second to fourth storey walls of the north face were
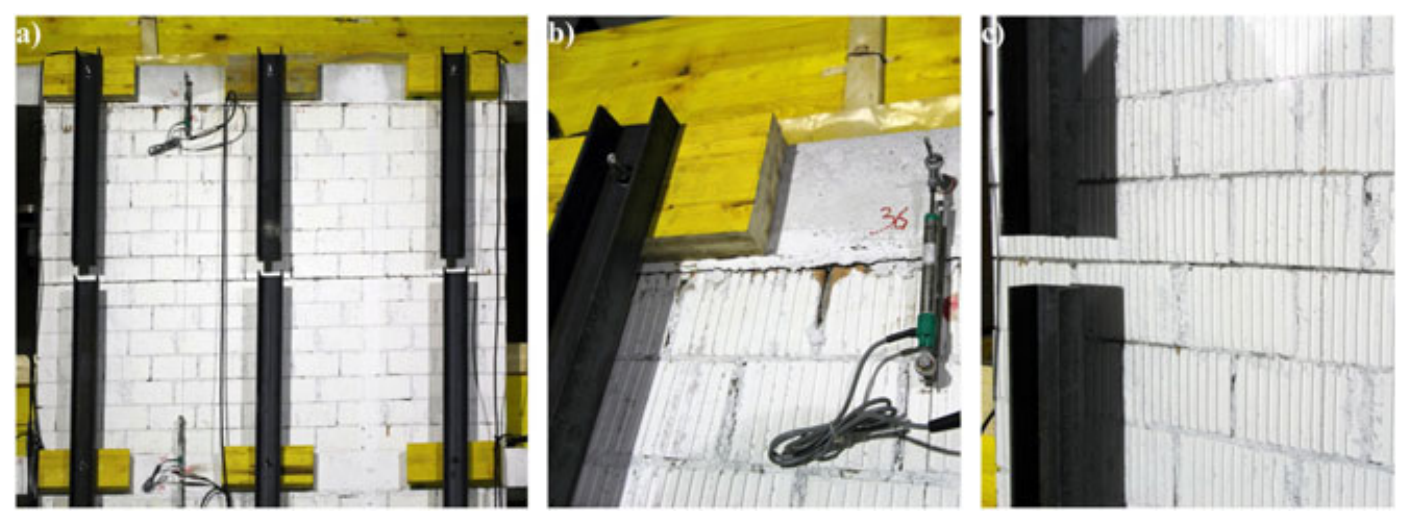

Figure 3. Damage in the fourth storey out-of-plane loaded wall on the north side of the structure: (a) full wall view, (b) detail of the top crack and (c) detail of the midheight crack. 
observed. The wall on the top storey clearly hit the inner support structure while the second and third storey walls did not touch the support structures. The mechanism of the top storey wall included the formation of bed joint cracks at the top and bottom and at midheight of the wall, which was confirmed by an inspection after the test (Figure 3).

The second and third storey walls did not hit the support structure but showed clear out-of-plane rocking displacements. Both walls formed hinges at the top and bottom of the walls. The third hinge, necessary for forming a mechanism and developing large out-of-plane displacements, formed at midheight for the second storey wall and at approximately three quarters of the storey height for the third storey wall. Unlike the walls of the north face, the walls of the south face did not show any visible out-of-plane displacements.

\subsection{Discussion of recorded data for out-of-plane response of unreinforced masonry walls}

The seismic performance of the out-of-plane loaded URM walls and the influence of the flanking elements are documented in Figure 4. The figure presents the horizontal out-of-plane displacements of the second, third and fourth storey walls on the north and south ends of the structure (Figure 4a and $4 \mathrm{~b}$, respectively). The out-of-plane displacement $\Delta_{\text {oop }}$ is defined by

$$
\Delta_{\text {oop }}=\Delta_{\mathrm{m}}-\frac{\Delta_{\mathrm{top}}-\Delta_{\mathrm{bot}}}{2}
$$

where $\Delta_{\mathrm{m}}$ is the relative displacement between the midheight of the wall and the bottom slab measured by a potentiometer and $\Delta_{\text {top }}$ and $\Delta_{\text {bot }}$ are horizontal slab displacements at the top and bottom of the wall obtained from the optical measurements.

Figure 4 shows the maximum and minimum values of the out-of-plane displacement for tests 6,8 and 9, corresponding to PGA values of $0.6,0.7$ and $0.9 \mathrm{~g}$, respectively (test 7 represented an aftershock and had a PGA of $0.4 \mathrm{~g}$ ). For the previous tests, the out-of-plane displacements had been very limited. Positive values in Figure 4 represent displacements towards the south. Therefore, positive displacements represent inward displacements for the north walls and outward displacements for the south walls.

Figure 4 shows that the north walls experienced significantly higher out-of-plane displacement than south walls. The minimum and maximum displacements of the fourth storey walls during the last test were $-20 \mathrm{~mm}$ and $+63 \mathrm{~mm}$ for the north wall but only $-7 \mathrm{~mm}$ and $+4 \mathrm{~mm}$ for the south wall. The north walls were flanked by URM walls while the south walls were flanked by the RC walls. These flanking elements had a significant influence on the boundary conditions and therefore on the response of the out-of-plane loaded walls.

Figure 4 also shows that for the south walls, the displacement profiles are fairly symmetrical and the displacement demands in the north and south directions are comparable. For the north walls, however,

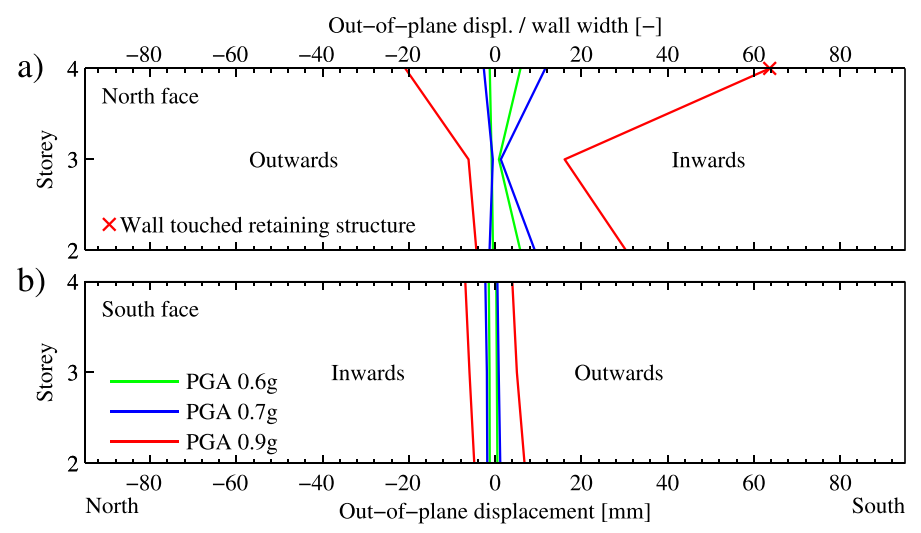

Figure 4. Out-of-plane horizontal displacement profiles: (a) north walls, which are flanked by URM walls, and (b) south walls, which are flanked by RC walls. 
the out-of-plane displacements are significantly larger in the south direction than in the north direction. These results suggest that the loading direction affects the boundary conditions when the flanking elements are URM walls but not when the flanking elements are RC walls.

The observed behaviour can be explained with a schematic diagram depicting global in-plane behaviour of the structure (Figure 5). Because of the overturning moment, the axial force in the outer structural elements varied with the loading direction. When the structure was pushed from south to north, the axial load in the structural elements on the north side increased, and the axial load decreased in the structural elements on the south side. The opposite happened when the seismic load was reversed. The loading direction had therefore an influence on the axial force to which the out-of-plane loaded walls, which were located at the perimeter of the building, were subjected.

Additionally, the kinematic boundary conditions are largely dependent on the flanking elements: on the north side, the RC slab was simply supported on the in-plane loaded URM walls and could therefore uplift when the axial load was reduced and the in-plane URM walls rocked. At the instant when the slab uplifted, the vertical restraint to the north out-of-plane loaded wall reduced and rendered it vulnerable to out-of-plane excitation. Note that because of the elongation of the wall when rocking out of plane, the axial force in the out-of-plane loaded wall is not necessarily zero when the slab uplifts from the in-plane loaded wall. On the south side, the RC walls of second, third and fourth storeys did not change their length because yielding of the longitudinal reinforcement of the RC walls remained limited to the first storey. The RC walls restrained therefore the $\mathrm{RC}$ slabs from uplifting and provided continuously a vertical restraint to the out-of-plane loaded wall. The URM wall could therefore resist the outof-plane loading by arching action.

These observations are supported by the data for the fourth storey URM wall on the north side, which is presented in Figure 6. It includes the displacement time history of the fourth storey slab with respect to the foundation and with respect to the third storey slab (Figure 6a and 6b); the variation of the vertical distance between the two RC slabs framing the wall (Figure 6c) and the uplift of the top slab from the wall (Figure 6d), where positive values correspond to an increase of distance; and the out-of-plane midheight horizontal displacements of the wall, where positive values correspond again to displacements towards south (Figure 6e).

The figure shows that the peak out-of-plane displacement (at 9.6 s) occurs simultaneously to the peak uplift of the slab of $10.7 \mathrm{~mm}$, confirming the interaction between slab uplift and vulnerability to out-of-plane deformations. Note that the uplift of the slab from the wall is

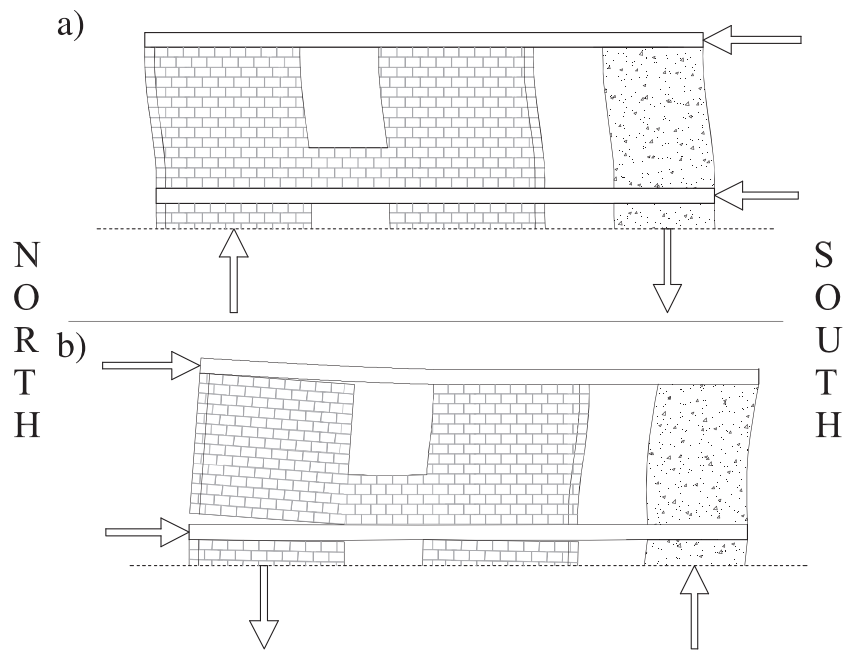

Figure 5. Schematic diagram of the effect of the loading direction: (a) loading from south to north and (b) loading from north to south. 

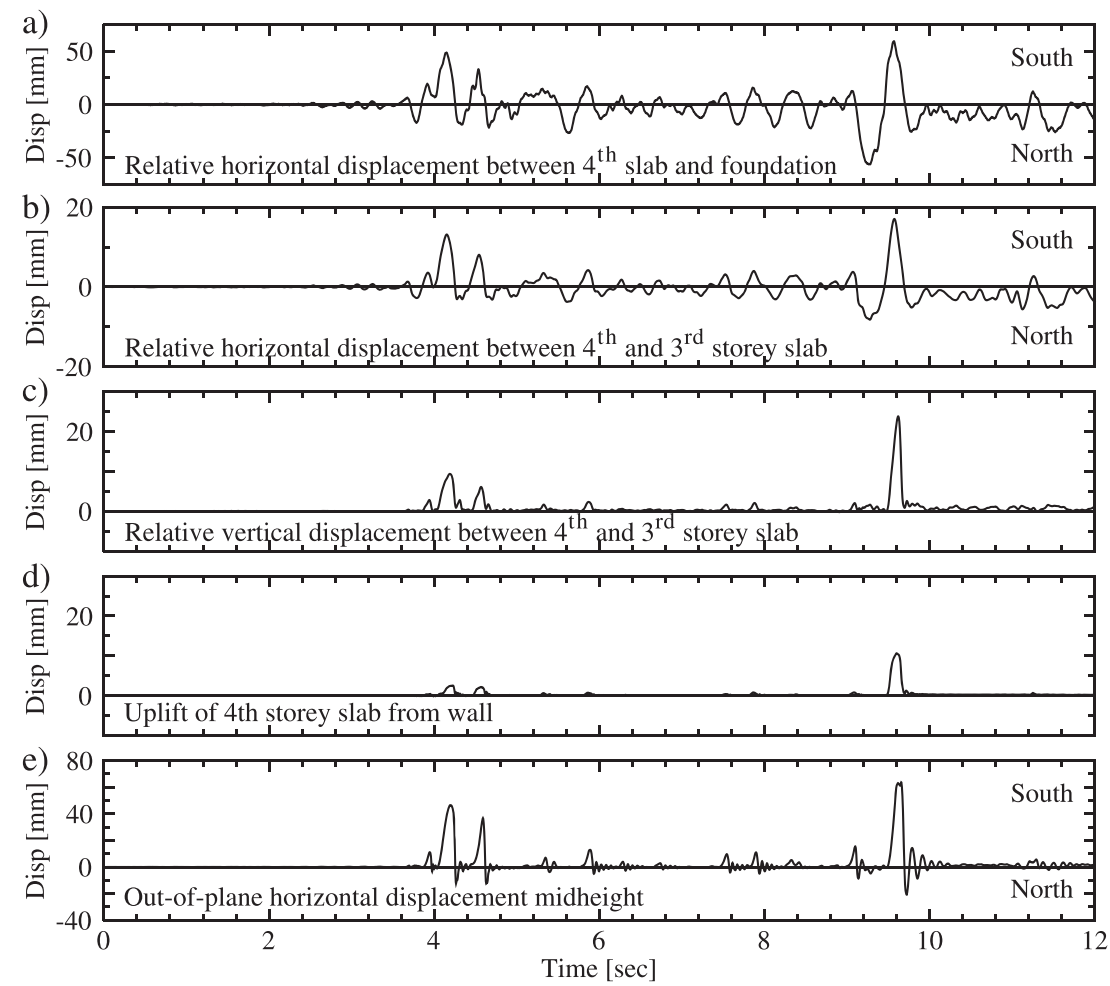

Figure 6. Time histories of: (a) horizontal displacement of the top storey slab with respect to the foundation, (b) horizontal displacement of the top storey slab with respect to the third storey slab, (c) relative vertical displacement of the RC slab at the top of the wall with respect to the slab at the bottom of the wall, (d) uplift of the top slab from the wall and (e) out-of-plane horizontal displacement at the midheight of the wall. All plots refer to the fourth storey north side wall.

much smaller than the relative vertical displacement between fourth and third storey slabs, which reached a maximum value of $23.8 \mathrm{~mm}$ before collapse. The difference is explained by the elongation of the wall due to rocking. The maximum value of out-of-plane midheight displacement of $63 \mathrm{~mm}$ corresponds to the maximum displacement allowed by the retaining structure for a rocking mechanism with hinges at the extremities and at midheight of the wall (the one experienced by the wall according to the horizontal cracks observed after the test; Figure 3). This proves that the wall, during the last test, touched the internal retaining structure and would have collapsed out of plane had the retaining structure not been installed.

\section{DISCRETE ELEMENT MODELLING}

The out-of-plane response of the north wall that failed will be analysed by means of a discrete element model using the commercial software UDEC [14]. The discrete or distinct element method (DEM), which is based on the work of Cundall [20] in the early 1970s, has been increasingly used over the years to analyse masonry structures. With DEM, the structure is modelled as an assemblage of discrete blocks, which can be either rigid or deformable. The blocks are separated by joint interfaces, along which the blocks can detach or slide without limit on relative displacement or rotation. Because of these features, DEM is particular suitable for analysing the dynamic behaviour of rocking masonry structures; past studies include investigation of the seismic behaviour of single blocks or block assemblages [21, 22, 25], masonry arches [23, 24], masonry facades [25, 26], free-standing columns [27, 28] and entire historical structures $[29,30]$. 
This section describes the model geometry, the assigned material properties, the definition of the boundary conditions and the assumptions with regard to the assigned damping for the dynamic analyses.

\subsection{Geometry and material properties}

The 2D model represents a cross section of one of the out-of-plane loaded URM walls (Figure 7). The model consists of 14 equal-sized blocks for the brick rows and two blocks that represent the top and bottom slabs. The block of the top slab is subdivided into two blocks: the outer block, to which the boundary conditions in terms of velocity histories are applied (Section 3.2), and the smaller inner block, which is in contact with the top brick. The interfaces between the outer block and the inner block are assigned zero shear strength. Hence, when the outer block uplifts from the wall, the inner block slides downwards and lies on the top brick of the wall without applying an axial force to the wall (more precisely, the applied axial force at the top of the wall corresponds to the weight of the inner block, which is $0.096 \mathrm{kN} / \mathrm{m}$ ). The interface between the inner block and the top brick is assigned the same interface properties as the interfaces between brick units. Because of the cohesive strength of the interface, the inner block prevents the sliding between top slab and wall, even if the wall uplifts. This top boundary condition was specified because appreciable sliding between wall and top slab was not observed in the test (Section 2.3). Most likely, the mortar 'fingers' reaching into the hollow-core clay brick helped to prevent any sliding displacement.

The mortar joints are represented by interfaces of zero thickness. The height of the bricks was therefore increased from the actual 95 to $100 \mathrm{~mm}$ to include also the average thickness of a mortar joint. The bricks are $95 \mathrm{~mm}$ wide. The block corners are rounded off with a radius $r$, which is an input parameter to the model (Figure 7c). This parameter defines also the position of the two sets of springs from the outer wall edge that represent the axial and shear properties of the interface. Considerations with regard to its value and its influence on the dynamic response are presented in Section 4.4.

In this paper, the blocks representing the masonry units are rigid, and the deformability is entirely allocated to the interfaces that represent the mortar joints. This hypothesis is typically reasonable for low to moderate axial load ratios. The joints were modelled as interfaces to which a Mohr-Coulomb constitutive model was assigned. All interface properties were derived

a)

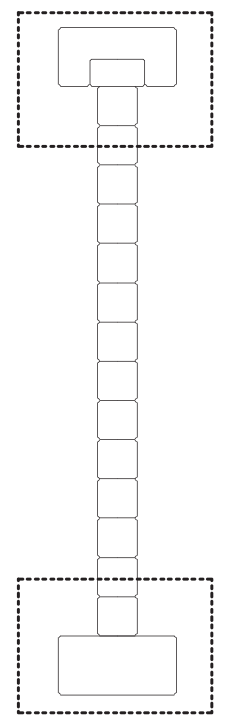

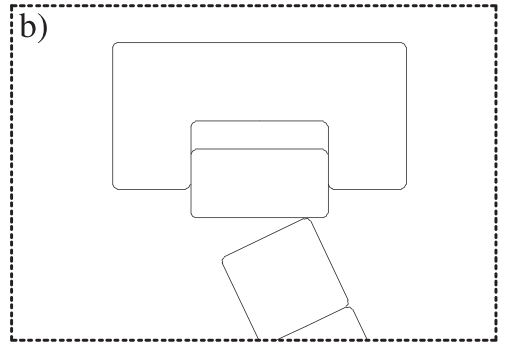

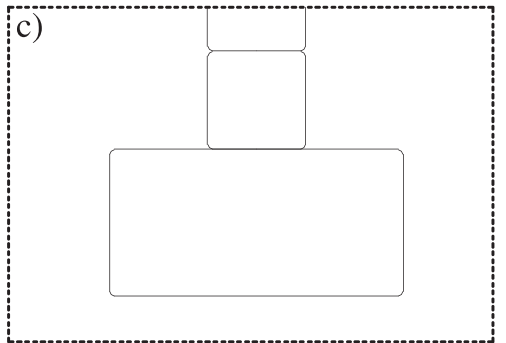

Figure 7. UDEC model: (a) geometry of the UDEC model, (b) detail of the top support when the top slab uplifts (deformation exaggerated) from the wall and (c) detail of brick with rounded corners. 
from standard material tests results (Table I), which involved vertical compression tests on masonry units and shear triplet tests [19]. The test units required for these standard tests were only constructed once and not repeatedly for each storey of the building. Mortar samples were, however, taken regularly during the construction of the shake table test unit and the construction of the test units for material testing. Standard mortar tests showed that the mortar used for the construction of the material test units was stronger than the mortar used for the construction of the fourth storey walls. Also, material test properties had been computed with regard to the gross width of the wall $(b=95 \mathrm{~mm})$ while the effective width of the interfaces in numerical model was only $b_{\text {eff }}=b-2 r=85 \mathrm{~mm}$. To account for these differences, the interface properties of the numerical model were computed as follows: the friction coefficient was obtained directly from the triplet tests and corresponds to a friction angle $\alpha_{\text {Triplet }}$ of $35^{\circ}$.

$$
\mu_{\mathrm{UDEC}}=\mu_{\text {Triplet }}=0.70
$$

The cohesion assigned to brick interfaces in the numerical model was computed as the cohesion obtained from shear triplet tests times the ratio of the mortar tensile strength of the fourth storey walls $\left(f_{\mathrm{tm}}\right.$, Storey 4$)$ and the mortar strength of the triplets $\left(f_{\mathrm{tm}}\right.$, Triplet $)$ and the ratio of nominal to effective wall width:

$$
C_{\mathrm{UDEC}}=c_{\text {Tripiet }} \cdot \frac{f_{\mathrm{tm}, \text { Storey } 4}}{f_{\mathrm{tm}, \text { Triplet }}} \cdot \frac{b}{b-2 r}=0.23 \cdot \frac{2.62}{3.23} \cdot \frac{95}{85}=0.209 \mathrm{MPa}
$$

The tensile strength assigned to brick interfaces in the numerical model was estimated from the cohesion $c_{\text {Triplet }}$ and the friction coefficient $\mu_{\text {Triplet }}$ assuming a parabolic tension cutoff:

$$
f_{\mathrm{t}, \text { Triplet }}=\frac{c_{\text {Triplet }}}{2 \mu_{\text {Triplet }}}=\frac{0.23}{2 \cdot 0.7}=0.164 \mathrm{MPa}
$$

In the numerical model, the joint behaviour is represented by two springs at the extremities of the joint where each spring is assigned the strength corresponding to half the joint length. The moment resistance of a joint subjected to zero axial force is therefore:

$$
M_{\mathrm{UDEC}}=f_{\mathrm{t}, \mathrm{UDEC}} \cdot \frac{(b-2 r)^{2}}{2}
$$

In reality, assuming a linear stress profile, the moment resistance would be (accounting again for the difference in mortar strength between fourth storey and triplets):

Table I. Masonry properties from standard material tests (Petry and Beyer [17]; Beyer et al. [19]).

\begin{tabular}{lr}
\hline E-modulus of the masonry for vertical compression $E_{\mathrm{m}}$, wallettes $(\mathrm{GPa})$ & 4.50 \\
Poisson ratio $v_{\text {Wallette }}(-)$ & 0.20 \\
Cohesion $c_{\text {Triplet }}(\mathrm{MPa})$ & 0.23 \\
Friction coefficient $\mu_{\text {Triplet }}$ & 0.70 \\
Masonry compressive strength $f_{\mathrm{cm}}$, Wallette $(\mathrm{MPa})$ & 5.66 \\
Tensile strength of mortar for triplet test units $f_{\mathrm{tm}}$, Triplet $(\mathrm{MPa})$ & 3.23 \\
Tensile strength of mortar used for the construction of the shake table test unit $f_{\mathrm{tm}}$, Storey4 $(\mathrm{MPa})$ & 2.62 \\
Compressive strength of mortar for wallettes test units $f_{\mathrm{m}}$, Wallette $(\mathrm{MPa})$ & 13.95 \\
Compressive strength of mortar used for the construction of the shake table test unit $f_{\mathrm{m}, \text { Storey4 }}(\mathrm{MPa})$ & 7.04 \\
\hline
\end{tabular}




$$
M=f_{\mathrm{t}, \text { Triplet }} \cdot \frac{f_{\mathrm{tm}, \text { Storey } 4}}{f_{\mathrm{tm}, \text { Triplet }}} \cdot \frac{b^{2}}{6}
$$

The tensile strength assigned to brick interfaces in the numerical model was therefore set to:

$$
f_{\mathrm{t}, \mathrm{UDEC}}=\frac{f_{\mathrm{t}, \text { Triplet }}}{3} \cdot \frac{f_{\mathrm{tm}, \text { Storey } 4}}{f_{\mathrm{tm}, \text { Triplet }}} \cdot \frac{b^{2}}{(b-2 r)^{2}}=0.055 \mathrm{MPa}
$$

The friction coefficient was obtained directly from the triplet tests and corresponds to $\mu_{\mathrm{UDEC}}=\mu_{\text {Triplet }}=0.7$. The elastic modulus $E_{\mathrm{m}}$, wallette and the Poisson's ratio $v_{\text {Wallette }}$ of the masonry were obtained from compression tests on masonry wallettes. To account again (i) for the fact that the compression strength of the mortar used for the construction of the fourth storey wall $\left(f_{\mathrm{m}}\right.$, Storey 4$)$ was less than that of the mortar used for the construction of the wallettes $\left(f_{\mathrm{m}}\right.$, wallette $)$ and (ii) for the ratio of nominal to effective wall width, the normal stiffness of the brick interface was computed as:

$$
K_{\mathrm{nn}}=\frac{E_{\mathrm{m}}}{h_{\text {block }}} \cdot\left(\frac{f_{\mathrm{m}, \text { Storey } 4}}{f_{\mathrm{m}, \text { Wallette }}}\right)^{0.3} \cdot \frac{b}{b-2 r}=\frac{4.50}{0.1} \cdot\left(\frac{7.04}{13.95}\right)^{0.3} \cdot \frac{95}{85}=41.0 \frac{\mathrm{GPa}}{\mathrm{m}}
$$

This equation uses the following relationships between mortar strength $f_{\mathrm{m}}$, brick strength $f_{\mathrm{b}}$, masonry compressive strength $f_{\mathrm{k}}$ and the elastic modulus of the masonry $E_{\mathrm{m}}$ [31]:

$$
\begin{aligned}
& E_{\mathrm{m}}=1000 \cdot f_{\mathrm{k}} \\
& f_{\mathrm{k}}=K \cdot f_{\mathrm{b}}^{0.7} \cdot f_{\mathrm{m}}^{0.3}
\end{aligned}
$$

The shear stiffness was computed as $\left(v_{\mathrm{UDEC}}=v_{\text {Triplet }}\right)$ :

$$
K_{\mathrm{tt}}=\frac{K_{\mathrm{nn}}}{2(1+v)}=\frac{41}{2(1+0.2)}=17.1 \frac{\mathrm{GPa}}{m}
$$

The interfaces between bricks and slabs were assigned the same stiffnesses as the interfaces between two bricks. This accounted for the fact that the masonry flexibility resulted mainly from the joints and not from the bricks, which would have justified a higher joint stiffness for the interfaces between wall and slabs.

The masonry wallettes had not been weighed, and therefore, the density of masonry was estimated as $\rho_{\mathrm{m}, \text { UDEC }}=1000 \mathrm{~kg} / \mathrm{m}^{3}$. The Mohr-Coulomb law implemented in UDEC obeyed an elastic-brittle relationship in tension; that is, upon reaching the tensile strength capacity, the tensile strength drops immediately to zero. However, the cohesion was not reduced upon reaching the shear strength of the interface.

\subsection{Definition of the boundary conditions}

In UDEC, dynamic boundary conditions are defined as velocity histories applied at the rigid block centre. The wall model was loaded in three steps: first, the gravity load of the wall itself was applied as vertical acceleration of $9.81 \mathrm{~m} / \mathrm{s}^{2}$. Second, the axial force was applied as a constant downward velocity over a duration $\Delta t$ of the top block. The applied displacements were computed to yield an axial force of $15.5 \mathrm{kN} / \mathrm{m}$ at the base of the wall. The axial force was obtained from a TREMURI [32] model of the test unit, which was validated by Mandirola [33] to assess the in-plane behaviour of 
the test unit. Third, the seismic loading of the wall was applied as horizontal and vertical velocity time histories at the outer top and the bottom blocks, which represent the slabs. These velocity time histories were derived from the displacement histories of the slabs, which were recorded by the optical measurement system [19]. The rotation of the top and bottom slabs was set to zero because optical measurements showed that the rotations had been rather small (maximum value of $3.4 \times 10^{-3}$ ).

\subsection{Modelling of the damping}

Damping was added through stiffness-proportional Rayleigh damping, with the primary objective of damping out higher frequency vibrations, which can cause individual blocks to unrealistic vibrate apart in the computational model [24]. This was carried out by heavily damping the natural frequency associated with rotational vibration of individual bricks, while minimising the damping at lower frequencies, which govern mechanism displacements [24]. The damping matrix is therefore:

$$
C=\beta \cdot K
$$

where $K$ is the stiffness matrix. The rocking frequency $\omega_{\mathrm{r}}$ of a single block representing one of the brick rows was computed, and a fraction of critical damping of $\xi$ was assigned to this frequency, which can be approximated by [24]:

$$
\omega_{\mathrm{r}}^{2}=\frac{3 \cdot E_{\mathrm{m}, \mathrm{UDEC}} \cdot b(b-2 r)^{2}}{2 \cdot \rho_{\mathrm{m}, \mathrm{UDEC}} \cdot h_{\mathrm{b}}^{2} \cdot\left(b^{2}+h_{\mathrm{b}}^{2}\right)}
$$

The $\beta$ parameter is therefore:

$$
\beta=2 \cdot \frac{\omega_{\mathrm{r}}}{\xi}
$$

The damping coefficient $\xi$ could not be determined from experimental results. For this reason, Section 4.3 investigates the sensitivity of the dynamic response to the assumed value of $\xi$.

\section{VALIDATION OF THE NUMERICAL MODEL AGAINST EXPERIMENTAL RESULTS}

To validate the numerical model, the fourth storey wall of the north face was modelled, and the numerical results in terms of out-of-plane displacement at midheight, top and base rotation and failure mechanism were compared with the experimental response. The final model included a block rounding $r=5 \mathrm{~mm}$ and a damping coefficient of $\xi=20 \%$. First, the model was validated for this final parameter configuration. Then, the sensitivity of the results with respect to $r$ and $\xi$ was tested.

\subsection{Validation of the chosen model}

The model was validated for test 9, during which the wall hit the retaining structure at $9.6 \mathrm{~s}$, which will be considered in the following as the point of collapse. Figure 8a presents the comparison of the experimental and numerical time histories of out-of-plane displacements at midheight of the wall; the out-of-plane displacement is again defined as the horizontal displacement at midheight of the walls minus half the relative displacement between the top and bottom slabs (Section 2.4). The numerical model is able to accurately predict the overall global behaviour of the wall. The model estimates the mechanism rather well: at $4.2 \mathrm{~s}$, the hinge forms one and at collapse three rows too high when compared with the experimental observations (Figure 9).

Figure $8 \mathrm{~b}$ shows the comparison between the experimentally observed uplift of the slab from the top brick (computed as average displacement of the two potentiometers at the top of the wall; Figure 2) and 
the vertical movement of the sliding element with respect to the top element recorded during the numerical analyses. Before reaching collapse of the wall, at $9.6 \mathrm{~s}$, the vertical movement of the slider is less than $9.7 \mathrm{~mm}$. It seems plausible that the 'mortar fingers' that reached into the bricks accommodated this movement and modelling the top boundary condition with a slider (Section 3.1) therefore justified. The relative movement between slab and slider further confirms that the arching action, which requires the transmission of a vertical load, was lost. Note that the movement of the slider is much less than the increase in distance between the bottom and top slabs, which reached a maximum value of $23.8 \mathrm{~mm}$ before collapse (Figure 8). The difference is explained by the elongation of the wall due to rocking. Finally, Figure $8 \mathrm{c}$ and $8 \mathrm{~d}$ compare the experimental and numerical values of the top and bottom rotations of the wall, respectively; also for these parameters, there is a good correlation between the two sets of results.

\subsection{Effect of predamage}

In the experiment, the building was subjected to nine runs, and only the last one led to the out-of-plane collapse of the fourth storey wall. It remains, however, open in which regard the previous runs influenced the response during the ninth run. Although a visual inspection after run 8 had not revealed any significant damage such as flaking off of the paint on the mortar joints, which would have hinted towards large compression strains in the mortar (Section 2.3), it cannot be excluded that
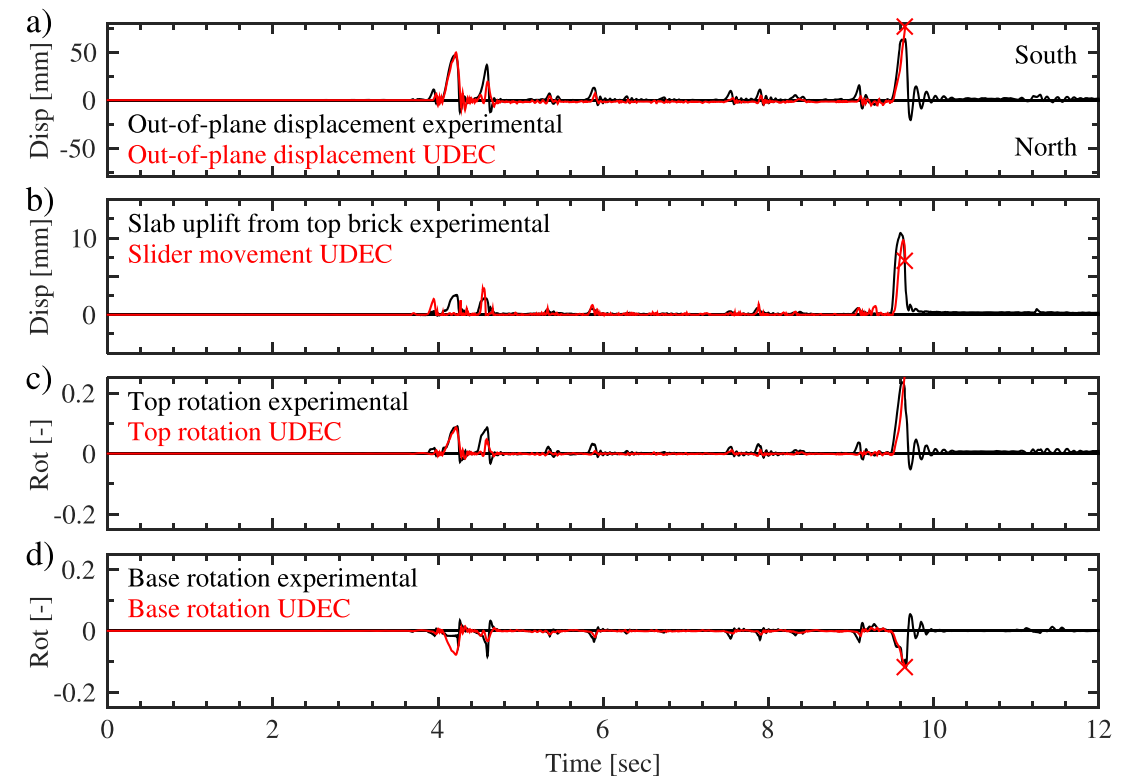

Figure 8. Comparison of numerical and experimental results for the final model of the fourth storey wall of the north face: (a) out-of-plane displacement at midheight, (b) uplift between slab and wall at the top, (c) relative rotation between slab and wall at the top and (d) relative rotation between slab and wall at the base.

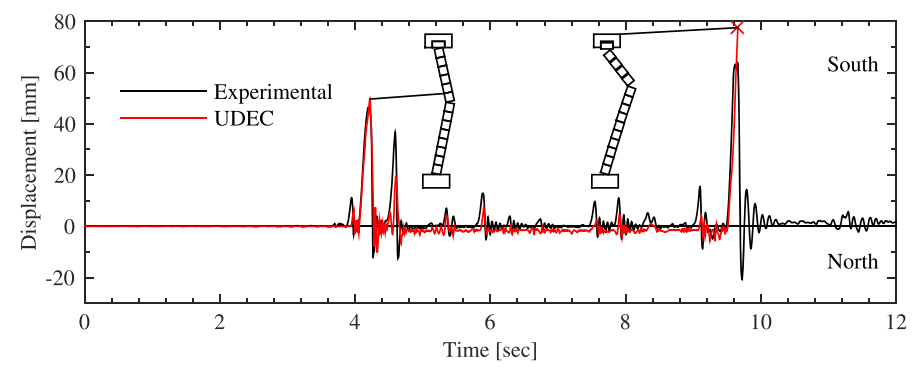

Figure 9. Comparison of experimental and numerical out-of-plane displacement with deformed shapes at $4.2 \mathrm{~s}$ and at failure at $9.6 \mathrm{~s}$. 
hairline cracks had been present. To investigate the effect of the predamage, the wall was analysed by subjecting it first to run 8 and then to run 9 . At the end of run 8, the numerical model showed cracks at the top and bottom interfaces of the wall. Figure 10 shows that this predamage had only a minor influence on the out-of-plane displacement during run 9. The mechanism that formed at collapse was also unaffected by the predamage.

\subsection{Sensitivity to the chosen damping level}

The choice of the damping level for discrete element analyses has been discussed by several authors (e.g. $[23,24,27,28])$. The initial portion of the strong ground motion response of models was found to be rather insensitive to the damping level $[27,28]$ while continued strong shaking and the reduction in amplitude of the free vibration can be sensitive to the damping [27]. For rocking motions, the natural rocking period is not constant [34], and therefore, it is impossible to specify a constant level of damping for a given mode. Specifying 0\% damping at all frequencies not only can lead to a good approximation of the initial portion of the strong ground motion response [29] but also can lead to unrealistic vibration displacements at no-tension interfaces [25] and overestimation of the response to either continued strong shaking or large separated pulses in the ground motion [25, 30]. This overestimation can be limited by specifying a small stiffness-proportional damping level that eliminates the high-frequency rotational vibration of individual blocks [24]. To investigate the sensitivity of the results with regard to the assumed damping level, Figure 11 shows the out-of-plane displacement at midheight for damping ratios between $\xi=0 \%$ and $\xi=100 \%$ at the rocking frequency $\omega_{\mathrm{r}}$ (Eq. (13)). Because no mass proportional damping is specified, the damping level decreases with decreasing frequency. At the natural frequency of the wall (assuming a simply supported beam), the corresponding damping ratios vary therefore only between $0 \%$ and $1.0 \%$.

The results fall into several groups: for $0 \%$, failure occurs at the first peak at $4.2 \mathrm{~s}$. For the analyses with $\xi=5 \%$ and $10 \%$, the displacement histories show a very high-frequency content, which is related to the rocking of the individual blocks and suggests that the rocking motion of the individual blocks is not sufficiently damped. For the second group of analyses with $\xi=15-100 \%$, this high-frequency content largely disappears. All analyses of this second group predict wall failure at $9.6 \mathrm{~s}$. They differ with regard to the predicted mechanism (central hinge between rows 7 and 10) and the amplitude of the displacements prior to failure. Exceptions are the analyses with 50\% and $75 \%$ that predict large sliding displacements between blocks and no failure at $9.6 \mathrm{~s}$. These sliding displacements were not observed in the test; a numerical sensitivity study showed that they can be eliminated if the friction angle is increased from $35^{\circ}$ to $45^{\circ}$.

Of the six analyses of the second group, the one with $\xi=20 \%$ predicts the experimentally recorded displacements best. For these reasons, $\xi=20 \%$ at $\omega_{\mathrm{r}}=2570 \mathrm{~Hz}$ was chosen as the final damping ratio; this corresponds to a damping ratio of $0.20 \%$ at the natural frequency of the wall.

\subsection{Sensitivity with regard to the assumed block rounding}

The rounding of the blocks affects the location of the pivot points that characterise rocking, and the elastic out-of-plane displacements before the springs that represent the interface are damaged, and rocking starts. The position of the actual pivot point depends on the axial load ratio $[35,36]$, the

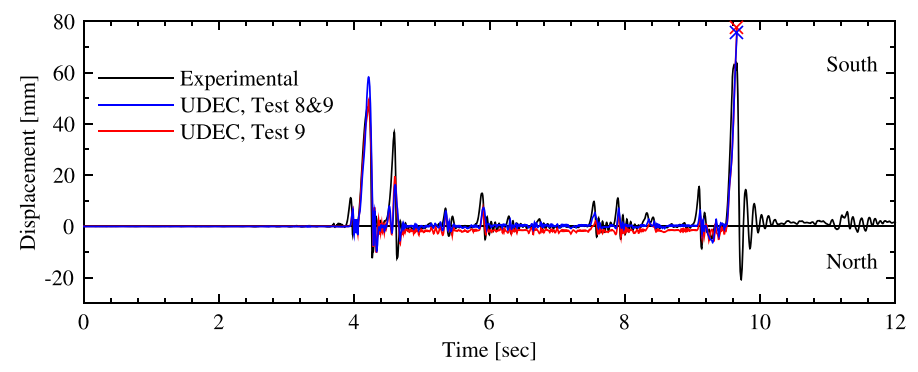

Figure 10. Midheight displacement of the fourth storey wall of the north face: comparison of numerical results when run 9 is applied to the undamaged wall and to the wall that had been predamaged by run 8 . 
state of degradation of the mortar joints [35] and the depth of the groove that is often carved into the mortar joint.

Under gravity load and when subjected to out-of-plane bending, the compression zone depth of the investigated wall can be approximated by:

$$
b_{\mathrm{c}}=\frac{N}{0.85 f_{\mathrm{cm}, \mathrm{UDEC}}}=15.5 \frac{\mathrm{kN}}{\mathrm{m}^{\prime}} \cdot \frac{1}{0.85 \cdot 4.61 \mathrm{MPa}}=3.96 \mathrm{~mm}
$$

where $N$ is the axial force under gravity loads and $f_{\mathrm{cm}}$, UDEC is the compressive strength of the masonry. If it is assumed that the pivot point is located at approximately half the compression zone depth, the rounding $r$ should be set to $b_{\mathrm{c}} / 2$ plus the depth of the groove $(\sim 2 \mathrm{~mm})$, that is, to $\sim 4 \mathrm{~mm}$. Figure 12 shows the numerical results for three block rounding values. Overall, the response is not very sensitive to this range of block rounding. For $r=5 \mathrm{~mm}$, the first peak is best predicted. For these reasons, $r$ was set to $5 \mathrm{~mm}$.
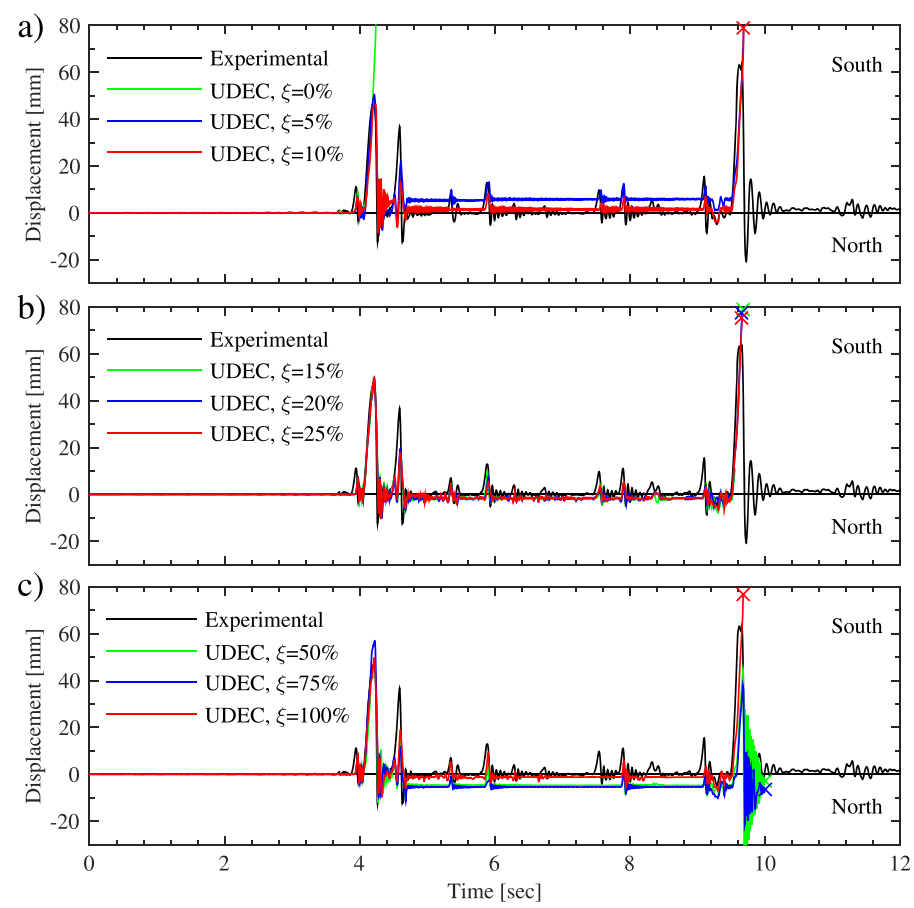

Figure 11. Midheight displacement of the fourth storey wall of the north face, sensitivity to damping level: (a) $\xi=0-10 \%$, (b) $\xi=15-25 \%$ and (c) $\xi=50-100 \%$.

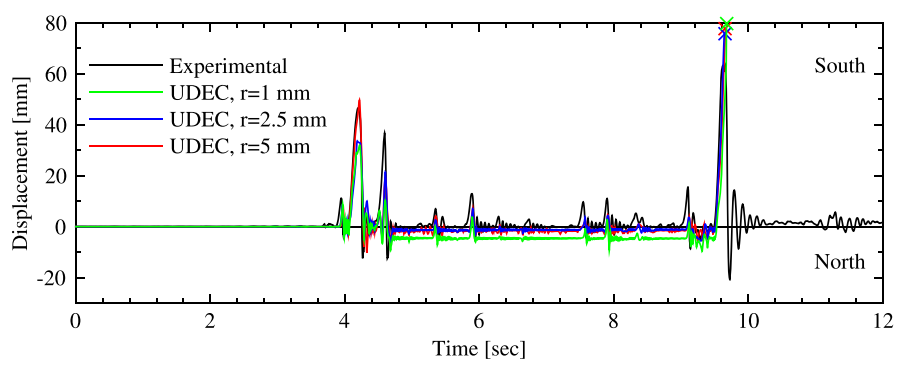

Figure 12. Midheight displacement of the fourth storey wall of the north face: sensitivity to block rounding. 


\section{THE INFLUENCE OF DYNAMIC BOUNDARY CONDITIONS ON THE OUT-OF-PLANE RESPONSE OF UNREINFORCED MASONRY WALLS}

This section investigates the influence of the dynamic boundary conditions on the out-of-plane behaviour of URM walls. The investigated parameters are the relative horizontal and relative vertical displacements between the bottom and top slabs, as well as the effect of the sliding restraint at the top of the wall.

\subsection{Effect of relative horizontal displacement between slabs}

Figure 13 shows the numerical results of the fourth storey wall for different horizontal excitations at the top and the bottom. The result labelled as 'UDEC, ref. model' corresponds to the analysis presented in Section 4.1, where the vertical and horizontal velocities of the top and bottom slabs are the slab displacements that were measured during the shake table test. Note that the maximum displacement relative to the foundation measured at the top floor slab was $59.4 \mathrm{~mm}$ (Figure 6), while the maximum difference between the horizontal displacements measured at the third and fourth floor slabs was $17 \mathrm{~mm}$.

To investigate the effect of differential top and bottom slab movements, analyses with the following top and bottom horizontal input velocities were carried out (Figure 13):

$$
\begin{aligned}
& v_{\mathrm{t}}=\frac{v_{4}+v_{3}}{2} \cdot(1+\alpha) \\
& v_{\mathrm{b}}=\frac{v_{4}+v_{3}}{2} \cdot(1-\alpha)
\end{aligned}
$$

where $v_{3}$ and $v_{4}$ are the horizontal velocities of the third and fourth storey slabs. The average velocity is therefore for all analyses the same. A value of $\alpha=0$ corresponds to an analysis where the average input motion is applied to the top and bottom of the wall and values larger than zero to analyses where the horizontal top and bottom motions are perfectly in phase but have different amplitudes. Figure 13 shows the analyses for $\alpha$ values between 0 and 0.10 . An $\alpha$ value of 0.04 leads to the same relative peak displacement as the reference model at $4.2 \mathrm{~s}$. Although all sets of input motions apply the same average acceleration of $\left(v_{3}+v_{4}\right) / 2$, the maximum out-of-plane displacements differ because different mechanisms are activated. The larger the relative displacement, the higher the location of the third hinge. However, all analyses lead as the reference model to collapse at $t=9.6 \mathrm{~s}$ (Figure 9).

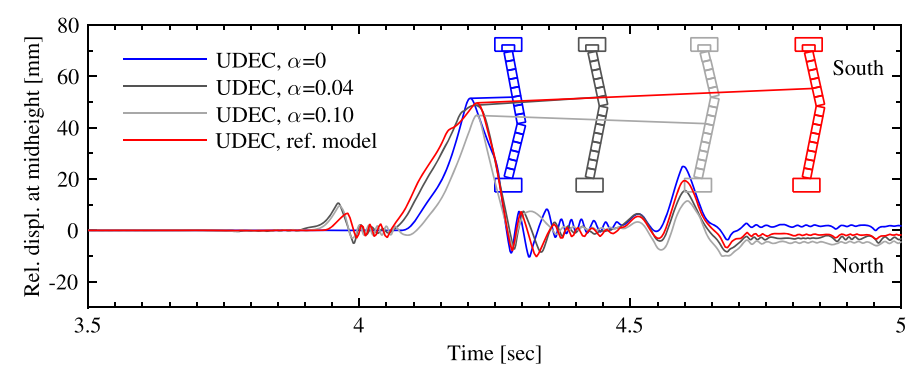

Figure 13. Midheight displacement of the fourth storey wall of the north face: sensitivity to the difference in horizontal input motion at the top and bottom of the wall. 


\subsection{Effect of relative vertical displacement between slabs}

The experimental results showed that the fourth storey wall developed its largest out-of-plane displacement when there was an uplift of the top slab due to rocking of the flanking wall (Section 2.4). At this instant, the vertical restraint at the top of the wall is weakened or completely absent, and the wall is more vulnerable to deform and collapse out of plane. It was shown that the fourth storey north wall collapsed for a differential vertical displacement of the supports of $23 \mathrm{~mm}$. Using the numerical model of the fourth storey north wall, test 9 was analysed for different levels of vertical excitation. The horizontal excitation applied to the top and the base of the wall was the same for all analyses while the vertical excitation were scaled to match values in a range of 0-100\% of the original vertical excitation (Figure 14).

Only for the original input ('UDEC, $100 \%$ uplift') is it possible to observe the large displacement at $4.2 \mathrm{~s}$. Furthermore, only for values of $60 \%$ and $100 \%$ of vertical excitation was wall collapse at $t=9.6 \mathrm{~s}$ observed. For $40 \%$ uplift, the out-of-plane displacement is smaller, and the wall does not collapse. For $80 \%$, the first peak was much smaller, and a phase shift of the rocking motion and the vertical displacement resulted in a large offset between blocks. For zero or small vertical uplift (0-20\%), limited or no out-of-plane deformations are observed. Zero or $20 \%$ vertical uplift is representative of the boundary conditions of a wall flanked by RC walls, for example, the fourth storey south wall, for which no significant out-of-plane displacement was observed (Figure 4b).

\subsection{Effect of sliding restraint at the top of the wall}

In the UDEC model, the top slab was modelled as composed by two elements: a main outer element and a secondary inner element that could slide vertically with regard to the outer element (Section 3.1). This modelling solution provides a horizontal restraint to the top of the wall when the top slab uplifted from the wall and aimed to represent the restraining action of the mortar fingers reaching into the holes of the bricks. Figure 15 shows the numerical result if this horizontal restraint is not modelled ('UDEC without slider'): the wall collapses out of plane at the first peak displacement, which does not capture the response observed in the test. This is also confirmed by the mechanism, which is a simple rigid body overturning mechanism with a single hinge at the base. Modelling this horizontal restraint ('UDEC with slider') seems therefore essential for capturing the experimental response. Further, for buildings of this type where slab uplift could occur, it is important to prevent complete separation and loss of lateral restraint at the top of the wall.
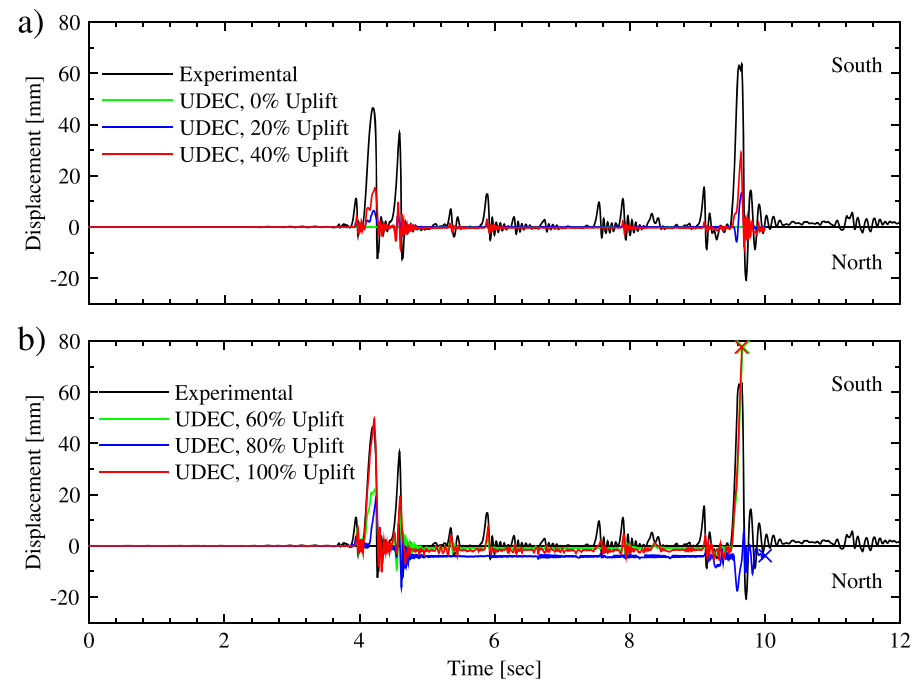

Figure 14. Midheight displacement of the fourth storey wall of the north face, sensitivity to vertical uplift: (a) $0-40 \%$ of vertical uplift and (b) $60-100 \%$ of vertical uplift. 


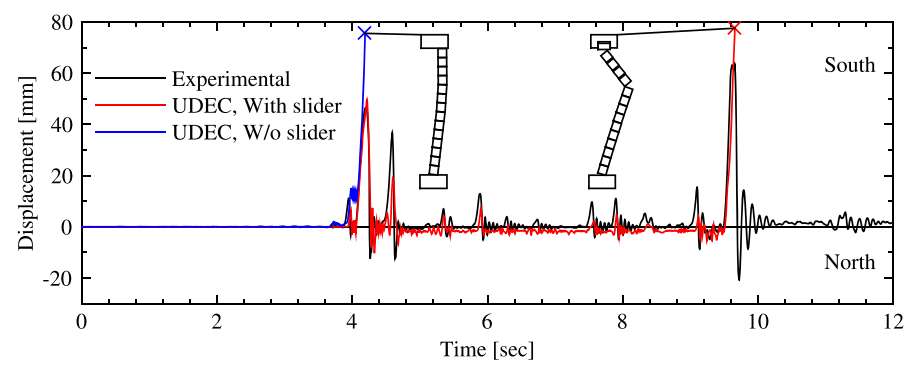

Figure 15. Midheight displacement of the fourth storey wall of the north face: different top restraint modelling options.

\section{CONCLUSIONS}

The paper investigates experimentally and numerically the out-of-plane response of URM walls in buildings with stiff RC slabs. A discrete element model was set up and validated against the response of the fourth storey wall that failed out of plane. Three new findings are presented:

- The out-of-plane response is controlled by the vertical restraint that is provided by the top slab. The largest out-of-plane displacements were observed when the top slab uplifted from the wall and the arching action was lost. This uplift was caused by rocking of flanking walls that were orthogonal to the wall that was loaded out of plane. Numerical analyses show that with less than $60 \%$ of this uplift, the wall would not have collapsed out of plane. The uplift of the slab from the wall seems therefore a key parameter in the out-of-plane response of URM walls in buildings with stiff RC slabs.

- Although the slab uplifts from the wall, it was still able to provide a horizontal restraint at the top of the wall. Numerical results show that if this horizontal restraint is omitted, a global overturning mechanism results without a hinge at midheight. In the experiment and the model with horizontal top restraint, a mechanism with a hinge at the top and bottom and approximately midheight formed.

- In the experiment, the motions naturally differed at the top and bottom of the walls because of the amplification of motions over the height of the structure and higher mode effects. The top slab of the wall that was analysed (fourth storey slab) was therefore subjected to larger horizontal accelerations than the bottom slab (third storey slab). Eliminating these relative horizontal accelerations, while maintaining the experimentally observed vertical slab uplift, modified the rocking mechanism that developed. This indicates not only that it was the absolute out-of-plane accelerations and the slab uplift that affected behaviour but also that the relative horizontal acceleration of the top and bottom of the wall also played a role. Therefore, differential floor motion may also be relevant for stiff slabs, not just for flexible slabs.

Both the effects of boundary conditions of an out-of-plane loaded URM wall that is flanked by URM walls that rock in plane and the effect of different relative horizontal accelerations at the top and bottom of the slab have not been described in the past. Hence, they neither have been considered by studies on which current design guidelines are based nor are current state-of-the-art analytical models capable to account for these effects (e.g. [35]). Future studies should therefore investigate these aspects further in order to understand better the mechanics behind these effects and to develop simple methods that can account for these effects in design or assessment guidelines for URM structures.

\section{ACKNOWLEDGMENTS}

The experimental research leading to these results received funding from the European Community's Seventh Framework Programme [FP7/2007-2013] for access to TREES laboratory of the European Centre for Training and Research in Earthquake Engineering under the grant agreement no. 227887. Additional financial support was received from the Office Fédéral de l'environnement in Switzerland. The reduced scale bricks were fabricated and donated by Morandi Frères SA, Switzerland. The authors appreciate and 
gratefully acknowledge all contributions. The authors would like to thank all members of the CoMa project team namely Prof B. Binici, Dr C. Butenweg, Prof M. A. Eberik, Dr T. Wenk, Dr P. Lestuzzi and Dr J. Varga. The authors are indebted to all members of the TREES laboratory and in particular the head of the laboratory, Prof A. Pavese, and to Dr Simone Peloso for their invaluable support during the entire duration of the project. The authors also thank Prof Paulo Lourenço, Prof Gianmarco de Felice and two anonymous reviewers for their comments on this study.

\section{REFERENCES}

1. Flanagan RD, Bennett RM. Bidirectional behavior of structural clay tile infilled frames. Journal of Structural Engineering 1999; 125(3):236-244.

2. Calvi GM, Bolognini D. Seismic response of reinforced concrete frames infilled with weakly reinforced masonry panels. Journal of Earthquake Engineering 2001; 2:153-185. DOI:10.1080/13632460109350390.

3. Pereira MFP, Pereira MFN, Ferreira JED, Lourenço PB. Behavior of masonry infill panels in RC frames subjected to in plane and out of plane loads, 7th International Conference on Analytical Models and New Concepts in Concrete and Masonry Structures, Krakow, 2011.

4. Da Porto F, Guidi G, Dalla Benedetta M, Verelato N. Combined in-plane/out-of-plane experimental behaviour of reinforced and strengthened infill masonry walls. 12th Canadian Masonry Symposium, Vancouver, British Columbia, 2013.

5. Morandi P, Hak S, Magenes G. Out-of-plane experimental response of strong masonry infills. 2nd European Conference on Earthquake Engineering and Seismology, Istanbul, 2014.

6. Mistler M, Anthoine A, Butenweg C. In-plane and out-of-plane homogenisation of masonry. Computers \& Structures 2007; 85(17-18):1321-1330. DOI:10.1016/j.compstruc 2006.08.087.

7. Kadysiewski S, Mosalam KM. Modeling of unreinforced masonry infill walls considering in-plane and out-of-plane interaction. PEER Report. 2009: 2008/102 (p. 144). Berkeley, California.

8. ABK. Methodology for mitigation of seismic hazards in existing unreinforced masonry buildings: wall testing, out-of plane. Technical Report ABK-TR-04, ABK, A Joint Venture of Agbabian Associates S.B. Barnes and Associates, and Kariotis and Associates, El Segundo, CA, USA, 1981.

9. Griffith MC, Lam NTK, Wilson JL, Doherty K. Experimental investigation of URM walls in flexure. Journal of Structural Engineering, ASCE 2004; 130(3):423-432. DOI:10.1061/(ASCE)0733-9445(2004)130:3(423).

10. Meisl CS, Elwood KJ, Ventura CE. Shake table tests on the out-of-plane response of unreinforced masonry walls. Canadian Journal of Civil Engineering 2007; 34(11):1381-1392. DOI:10.1139/L07-059.

11. Simsir CC, Aschheim MA, Abrams DP. Out-of-plane dynamic response of unreinforced masonry bearing walls attached to flexible diaphragms. 13th World Conference on Earthquake Engineering, Vancouver, B.C., 2004, Paper No. 2045.

12. Dazio A. The effect of the boundary conditions on the out-of-plane behaviour of unreinforced masonry walls. 14th World Conference on Earthquake Engineering, Beijing, China, 2008.

13. Penner O, Elwood K. Shake table study on out-of-plane dynamic stability of unreinforced masonry walls. 12th Canadian Masonry Symposium, Vancouver, B.B., 2013.

14. Itasca Consulting Group Inc. UDEC-universal distinct element code, version 6.0. Minneapolis, Minnesota, 2014.

15. Paparo A, Beyer K. Quasi-static cyclic tests of two mixed reinforced concrete-unreinforced masonry wall structures. Engineering Structures 2014; 71:201-211. DOI:10.1016/j.engstruct.2014.04.002.

16. Krawinkler H. Possibilities and limitations of scale-model testing in earthquake engineering. 2nd U.S. National Conference on Earthquake Engineering 1979, Stanford, California, pp: 283-292.

17. Petry S, Beyer K. Scaling unreinforced masonry for reduced-scale seismic testing. Bulletin of Earthquake Engineering 2014; 12:2557-2581. DOI:10.1007/s10518-014-9605-1.

18. Lunghi F, Pavese A, Peloso S, Lanese I, Silvestri D. Computer vision system for monitoring in dynamic structural testing. Role of seismic testing facilities in performance-based earthquake engineering. SERIES Workshop, Geotechnical, Geological and Earthquake Engineering 2012, 22, Springer, Netherlands. DOI: 10.1007/978-94-007-1977-4_9.

19. Beyer K, Tondelli M, Petry S, Peloso S. Dynamic testing of a four-storey building with reinforced concrete and unreinforced masonry walls: prediction, test results and data set. Bulletin of Earthquake Engineering 2015; 13(10):3015-3064.

20. Cundall PA. Computer model for simulating progressive large scale movements in blocky rock systems. Proceedings of the Symposium of International Society of Rock Mechanics, Nancy 1971; 1, Paper No. II-8.

21. Peña F, Prieto F, Lourenço PB, Campos Costa A, Lemos JV. On the dynamic of rocking motion of single rigid-block structures. Earthquake Engineering and Structural Dynamics 2007; 36:2383-2399. DOI:10.1002/eqe.739.

22. Winkler T, Meguro K, Yamazaki F. Response of rigid body assemblies to dynamic excitation. Earthquake Engineering and Structural Dynamics 1995; 24:1389-1408.

23. De Lorenzis L, DeJong M, Ochsendorf J. Failure of masonry arches under impulse base motion. Earthquake Engineering and Structural Dynamics 2007; 36:2119-2136. DOI:10.1002/eqe.719.

24. DeJong M. Seismic assessment strategies for masonry structures. Ph. D. dissertation. Massachusetts Institute of Technology, Cambridge, MA. 2009.

25. Al Shawa O, de Felice G, Mauro A, Sorrentino L. Out-of-plane seismic behaviour of rocking masonry walls. Earthquake Engineering and Structural Dynamics 2012; 41:949-968. DOI:10.1002/eqe.1168.

26. De Felice G. Out-of-plane seismic capacity of masonry depending on wall section and morphology. International Journal or Architectural Heritage: Conservation, Analysis, and Restoration 2011; 5:466-482. DOI:10.1080/ 15583058.2010.530339. 


\section{TONDELLI, K. BEYER AND M. DEJONG}

27. Psycharis IN, Papastamatiou DY, Alexandris AP. Parametric investigation of the stability of classical columns under harmonic and earthquake excitations. Earthquake Engineering and Structural Dynamics 2000; 29:1093-1109.

28. Papantonopoulos C, Psycharis IN, Papastamatiou DY, Lemos JV, Mouzakis HP. Numerical prediction of the earthquake response of classical columns using the distinct element method. Earthquake Engineering and Structural Dynamics 2002; 31(9):1699-1717. DOI:10.1002/eqe.185.

29. Azevedo J, Sincraian G, Lemos JV. Seismic behavior of blocky masonry structures. Earthquake Spectra 2000; 16(2):337-365. DOI:10.1193/1.1586116.

30. Psycharis N, Lemos JV, Papastamatiou DY, Zambas C, Papantonopoulos C. Numerical study of the seismic behaviour of a part of the Parthenon Pronaos. Earthquake Engineering and Structural Dynamics 2003; 32:2063-2084. DOI:10.1002/eqe.315.

31. CEN (2005) Eurocode 6: design of masonry structures-part 1-1: general rules for reinforced and unreinforced masonry structures EN 1996-1-1:2005. European Committee for Standardisation, Bruselles, Belgium.

32. Lagomarsino S, Penna A, Galasco A, Cattari S. TREMURI program: an equivalent frame model for the nonlinear seismic analysis of masonry buildings. Engineering Structures 2013; 56(11):1787-1799. DOI:10.1016/j. engstruct.2013.08.002.

33. Mandirola M. Non-linear macroelement modelling of experimental tests on masonry building specimens with rigid diaphragms. MSc thesis 2014, IUSS, Pavia, Italy.

34. Housner G. The behavior of inverted pendulum structures during earthquakes. Bulletin of the Seismological Society of America 1963; 53(2):403-417.

35. Doherty K, Griffith MC, Lam N, Wilson J. Displacement-based seismic analysis for out-of-plane bending of unreinforced masonry walls. Earthquake Engineering and Structural Dynamics 2002; 31(4):833-850. DOI:10.1002/eqe.126.

36. Costa AA, Arêde A, Penna A, Costa A. Free rocking response of a regular stone masonry wall with equivalent block approach: experimental and analytical evaluation. Earthquake Engineering and Structural Dynamics 2013; 42(15): 2297-2319. DOI:10.1002/eqe.2327. 